\title{
Research on the Application of Motivation Theory in the Management of College Students
}

\author{
Zhengyu Fan \\ Changzhou College of Information Technology, Changzhou, 213000, China
}

Keywords: Motivation theory, Colleges and universities, Student management.

\begin{abstract}
In the practice of college education, the student management is a new education task in the new period. Especially in the circumstances that the traditional rigid management has been insufficient to meet the practical work needs of the current student management, we shall introduce the flexible motivation management thought to the student management, which can effectively improve the current situation of student management, highlight the humanistic features of student management, promote the overall management level, and create good conditions for the advantage acquisition of the student management. In this article, we analyze the application of the motivation theory in the management of college students and we hope that it can promote the management of college students with a new development trend and provide effective support for the talent cultivation in colleges and universities.
\end{abstract}

\section{Introduction}

At the present stage and in the social background of the gradual deepening of reform and opening-up and the rapid popularization of internet, undergraduates are influenced by the social multicultural information in the growing process, and their values and growing features gradually become complex and diversified, which causes corresponding influence on the student management and a great challenge to the student management to some extent. Therefore, in the process of strengthening student management, colleges and universities shall explore and innovate actively, take new management methods for student management reasonably, and then assist the comprehensive management of student management with new management mechanism to get new management performance as soon as possible.

\section{Connotation of the motivation theory}

Based on the deep analysis of motivation, American management science research experts define the motivation properly, who think that in the process of influencing people, all conditions that people strive for conditions in the depth of their hearts, hopes and wishes, power and others are able to constitute the effective motivation, and it is mainly the basic status of human thinking activities. Therefore, with the function of motivation, we shall pay attention to stimulate people's motives and realize the induction of human behaviors, so as to produce a real internal driving force to drive people to constantly strive for the desired value goal. Thus it can be seen that, in the management science, we can stimulate the organization members' motives in virtue of development of the assistant management of the motivation theory, and drive them to constantly strive for and explore the realization of the organization's management objectives with various conditions. In the management of college students, if the motivation theory is applied reasonably, the student management can gradually show a new development trend, the overall management level will be improved, and it will have a crucial impact on the improvement of the whole quality of running colleges and universities ${ }^{[1]}$. Therefore, we shall actively try to use the motivation theory in the student management, reform and innovate the student management, and improve the management quality and optimize the 
management work, in order to provide corresponding guarantee for the sustained and stable operation of student management.

\section{The principles of applying the motivation theory in the management of college students that shall be insisted on}

In the management of college students, in order to apply the motivation theory reasonably and fully play the role of motivation function, we shall insist on following specific principles to carry out the student management and maximize to highlight the guiding function of motivation theory so as to create good conditions for the comprehensive optimization and implementation of the management of college students.

\section{Insist on the principle of equal emphasis on material motivation and spiritual motivation}

For the effective motivation implemented in the process of student management, we shall not only analyze the absolute value of motivation, but also survey its relative value comprehensively. Therefore, in order to highlight the effect of motivation furthest, we shall combine the material motivation and spiritual motivation effectively, recognize students' learning with material motivation, and guide students to learn more deeply with spiritual motivation to stimulate students' inherent learning motivation, improve students' learning enthusiasm, and effectively enhance the actual effect of the management of college students.

\section{Insist on the organic combination of positive motivation and negative motivation}

In the management of college students, we shall implement the motivation theory and provide corresponding guidance for the optimization and implementation of student management with the theory. In this process, we shall not only realize the importance of positive motivation, but also pay attention to the influence of negative motivation on students, and then make the motivation measures combined with rewards and punishments, so that students can consciously standardize and restrain themselves in the progressing process, go ahead along the correct development direction and become the talents who are unable to contribute to the society [2].

\section{Insist on the organic combination of intrinsic motivation and extrinsic motivation}

While researching and analyzing the motivation theory, we discover that motivation is composed of intrinsic motivation and extrinsic motivation. In order to fully highlight the function of motivation, we shall give consideration to both intrinsic motivation and extrinsic motivation at the same time, implement the motivation measure from hearts of student individuals, and the construction of external environment shall be matched with the students' inner development to play the function of motivation furthest, make students establish correct outlook on life and values in the growing process, and provide appropriate support and guarantee for the future development of students.

\section{Insist on the combination of group motivation and individual motivation}

In the growing process of students, group motivation and individual motivation can play a joint role, so teachers shall limit the corresponding group based on the implementation of effective motivation for individuals, take the group as unit and implement motivation measures for it, and stimulate students appropriately and motivate their sense of individual responsibility and collective responsibility, in order to improve the motivation effect ${ }^{[3]}$. Only in this way, the application of motivation theory in the management of college students can be effective, and the overall education level will be improved, which will influence the future development of students significantly.

\section{Effectively apply the measures of motivation theory in the management of college students}

From the above analysis, it can be seen that the effective application of motivation theory in the management of college students can improve the overall level of student management and also 
influence the future development of students significantly. Therefore, colleges and universities shall correctly understand the importance of student management, and actively explore the application of the motivation theory in the student management, in order to improve the current status of student management step by step, promote the overall level of student management, and provide a solid guarantee for the future development of students ${ }^{[4]}$. In terms of concrete operations, colleges and universities can create favorable conditions for the rational application of the motivation theory and provide corresponding support and guarantee for the comprehensive optimization and implementation of the student management from following aspects.

\section{Actively build a fair and reasonable motivation mechanism in colleges and universities}

If we want to achieve the ideal management performance in the management of collage students and ensure the guiding function of motivation theory is fully played, the most basic precondition is to build a fair and reasonable motivation mechanism, stimulate students' learning enthusiasm in virtue of the auxiliary function of motivation mechanism, and provide corresponding support and guarantee for the students' healthy growing. Therefore, in the research and analysis process of the current student management in China's colleges and universities, we shall systematically grasp the situations that the contemporary college students have strong comparison psychology and are very selfish, try integrating the learning objectives and ideas with the student management, guide the student management correctly, and in virtue of the guidance of motivation theory, make students realize the importance of correct outlook on life and values, strengthen students' sense of collectivism responsibility, and make right guidance for the healthy growth of students ${ }^{[5]}$. In the building process of motivation mechanism for students, we shall adhere to the principle of justice and equity to further enhance students' sense of identity and trust of the school's motivation, and promote the optimization and implementation of the motivation to ensure that the student management becomes effective in the background of new age.

\section{Make scientific behavioral objectives}

In the process of application of motivation mechanism in the assistance in carrying out student management, to make scientific behavioral objectives can play a guiding role correspondingly in the comprehensive management of the college students, to promote the effective comprehensive student management in the background of new age. From the perspective of psychological research, all human behaviors have obvious motivational characteristics in the process of life and development. If there is no motive, the behavior will certainly lose its due meaning little by little ${ }^{[6]}$. Therefore, with the function of motivation mechanism, colleges and universities shall try making scientific and rational behavioral objectives in the development process to guide undergraduates' behaviors, and provide effective driving force for all their living behavior to make them obtain a great sense of achievement after accomplishing the objectives, truly enhance students' confidence in life and learning, and provide corresponding support and guarantee for their future vocational development. In addition, in the research and setting process of behavioral objectives and based on the overall grasp of students' overall learning situation, we shall divide the students' learning ability at levels, and then set corresponding objectives according to the different levels, to ensure that students can complete tasks step by step, enhance their enthusiasm of participating in learning management, and let the students feel the challenge in learning and life to realize the inherent driving for student behaviors. In this way, the scientific behavioral objective can fully play the motivating role for students, and students also can gradually grow healthily.

\section{Set good examples in the student group}

Setting good examples in the student group can play the motivating role, guide students' growth, and create favorable conditions for the comprehensive optimization and implementation of student management. Therefore, in the background of current college education practice, we shall make use of students' competitive psychology to set the examples of model students based on the overall analysis of reality of the student management in this college, and publicize the selection criteria to all 
students [7]. In this way, on the one hand, we can take the force of examples to influence the students' thoughts and behaviors unconsciously; on the other hand, it can promote students to restrain their own behaviors continuously according to the selection criteria to become examples, improve their learning performance and comprehensive abilities, and get better development. It can be seen that setting good examples in the student group can improve the efficiency and effect of student management. In addition, in the student management, we shall note that the teachers themselves play the role of examples for students, so in the daily teaching and life, teachers shall standardize their own words and deeds consciously, and behave as examples for students to guide the students' behaviors positively and healthily, and improve the students' overall learning effect. Only in this way, the management of college students can become effective under the function of motivation theory, the comprehensive student management level can be improved overall, and it will has a crucial effect on students' sustained and stable development in the future society.

\section{Strengthen the construction of the motivation mechanism of trust and care}

In the students' comprehensive management practice, if teachers want to pass on their personal management thought to students effectively and are accepted by the student group, and play the role of personal management thought to promote the optimization and implementation of student management, the prerequisite is to obtain students' trust and improve the student management efficiently in virtue of students' trust. Therefore, in the current social background, for the management of college students, teachers shall firstly maintain the students' trust, so that students can feel the care from teachers in the learning activities. Meanwhile, in the process that teachers carry out the student management, they shall try delivering part of management work to the student representatives to enhance the management performance and deepen student groups' acceptance and trust of teachers through students' self-management, and further to build the motivation mechanism of trust and care and fully play the role of student management. Only in this way, the objectives of student management can be realized effectively and the comprehensive student management level will be enhanced further certainly, which will have a crucial influence on the overall and stable development of student management in the background of new age, and will play a critical role in the optimization and implementation of training college talents ${ }^{[8]}$. For example, in the process of organizing and carrying out student management, a university counselor not only delivers the power of student management to students, but also organizes to carry out class discussions regularly to let students speak out freely and analyze the existing problems in the student management, and propose recommendations for optimization and improvement according to students' opinions, so as to meet all students' needs in the student management, maintaining students ' interests, make the student management become effective in the background of new age, and provide effective support for the school education and teaching.

\section{Conclusion}

To sum up, the application of motivation theory in the management of college students can promote the maximum development of motivation effect and the acquirement of motivation effectiveness, and have an important affect on optimization and implementation of training of college talents. Therefore, in the student management practice in colleges and universities in the new age, we shall correctly understand the importance of motivation theory, and reform and innovate the motivation mechanism combined with guidance, in order to really play the important role of motivation mechanism, guide students' healthy growth, make corresponding strength for students' future overall development, promote students, and enhance students' overall learning effect.

\section{References}

[1] Zhang Heng, Tentative Analysis of Application of Motivation Theory in the Management of College Students, Youth, 2015(10), pp.162-162. 
[2] Wang Ning, Discussion on the Application of Motivation Theory in the Management of College Students, Journal of Seeking Knowledge Guide, 2015(13), pp.119-119.

[3] Li Dan, the Application of Motivation Theory in the Management of College Students, the Livings, 2015(9), pp.82-82.

[4] Song Weili, Tentative Analysis of Application of Motivation Theory in the Management of College Students, Contemporary Education Research and Teaching Practice, 2016(7), pp.23.

[5] Wu Hong, Tentative Analysis of Application of Motivation Theory in the Management of College Students, Academy, 2016(9), pp.34.

[6] Zheng Quanlei, Brief Discussion on the Application of Motivation Theory in the Management of College Students, China Training, 2015(6X), pp.108-108.

[7] Wang Zhifeng, the Application of Motivation Theory in the Management of College Students, Contemporary Education Research and Teaching Practice, 2016(8), pp.5.

[8] Ji Xinmiao, Cheng Xiaobo, Yu Qinglin et al, the Application of Motivation Theory in the Management of College Students, Journal of Sichuan Engineering Technical College, 2017(1), pp.55-57. 